Commonplace $\bullet$ Business of Knowing, august 2021

\title{
Re-thinking Academic \\ Publishing: The Promise of \\ Platform Cooperativism
}

Evgeniya Lupova-Henry, Ámbar Tenorio-Fornés

Published on: Aug 24, 2021

DOI: $10.21428 / 6 \mathrm{ffd} 8432.0 \mathrm{ed} 64224$

License: Creative Commons Attribution 4.0 International License(CC-BY 4.0). 
Sustainable, just, and equitable open access academic publishing may sometimes seem to be a utopia. There are just too many "buts" - "but the academic career depends on your scholarly output," "but you have to publish in 'high-ranking' journals. "Yes, there is much to say about the injustices of the academic publishing system, and how we got there and the need for "high-level" action to change funding models and incentives. Yes, it may seem that there are just too many factors outside our control.

\section{But are they?}

Or could we imagine a future where scholars are the ones at the helm of the scholarly publishing ecosystem? In this contribution, we propose to do just that: imagine a different - fairer, more economically sustainable, and inclusive - approach to open access. However, to do that, we need to think not only outside the scope of existing business and publishing models but also the existing organisational models.

\section{Platform cooperativism}

Although the number of new open access initiatives is growing, to many in academia the only thinkable options are framing these under for-profit or non-for-profit frameworks, each of these having their challenges, each in a way exploitative. Indeed, for-profit publishing models benefit a select few by exploiting academic research outputs. However, the not-for-profit models (such as many independent Diamond OA journals) often leverage unremunerated work seen as the "labour of love." This, however, may be just as exploitative of academics - especially early-career scholars providing their time and expertise free of charge in the hopes that this might help them to obtain stable employment in academia in some distant future.

We believe there is another way for scholarly publishing initiatives: platform cooperativism. $\underline{1}$ Cooperatives are defined as "people-centred enterprises jointly owned and democratically controlled by and for their members to realise their common socioeconomic needs and aspirations." 2 Platform coops take this idea of democratic decision-making and shared ownership and apply it to "online applications or websites [that are] used by individuals or groups to connect to one another or to organize services." $\underline{3}$ 
The platform cooperative movement is growing in many fields due to a general disillusionment with the predominant models of capitalist production. Conceptually related to the Occupy Wall Street movement, the ongoing attempts to decentralize the Internet, and the \#BuyTwitter initiative, platform cooperativism is taking hold and ushers in new ways of thinking about business models and business success, such as choosing an "exit" $\underline{4}$ to community over investor ownership. Platform cooperativism holds promise for revolutionising the platform economy through democratic ownership and fairer profit distribution, resulting in better pay, a higher sense of fulfilment for employee-owners and helping keep the profits in the communities $\underline{5}$ that these coops serve.

Academic publishing relies on digital processes and technologies and, increasingly, platforms. It is also plagued with inequality, unfair profit distribution and the evergrowing centralisation of control over the publishing process in the hands of large commercial players. $\underline{6}$ We believe that platform cooperativism is a promising approach that may allow the actors of the scholarly publishing ecosystem (such as journals, publishers, academic institutions, and individual academics) to take [back] the reins of academic publishing. Scholars touched upon this idea already in the early days $\underline{7}$ of platform cooperativism and came back to it more recently․ $\underline{8}$ and some initiatives in open access academic publishing have been presented under the 'cooperative' banner (although somewhat misleadingly $\underline{9}$ ). However, to date, the idea has not been 'stresstested' in academia. The key principles of platform cooperativism are $\underline{10}$ :

1. Broad-based ownership

2. Democratic governance

3. Co-design of the platform

4. An aspiration to open-source development and open data

Let's go through these principles to see how they can be applied to academic publishing and how they can benefit the ecosystem.

\section{Broad-based ownership and democratic governance}

Broad-based ownership and democratic governance of the platform implies that platform users, contributors, and workers (those maintaining and developing it) have shared control over the platform (its technological features, algorithms, data, production processes, job structures), collectively govern it based on 'one member, one vote' approach, and have a fair share in profit distribution. 
The academic community is increasingly recognising the need and the potential of collaborative approaches to the governance of the 'collective goods,' such as the academic research outputs. $\underline{11}$ Collective and consortial funding models $\underline{12}$ are taking hold to foster fairer open access publishing, allowing both equal "access to read" and "access to publish." Some of these models allow participating funding institutions to have a role in platform governance, $\underline{13}$ however these do not involve the broader academic community in decision-making. Platform cooperativism can help broaden the scope of stakeholders involved in platform governance allowing individual academics to have a say along with publishers, institutions and libraries. Indeed, as a form of 'broad-based stakeholder ownership' model, a platform coop is an organisation that is 'structurally and legally accountable to one or more classes of its most active participants' (Schneider 2018,_p.3-4). This allows to recognise the interests of those whose stake in a company may not (only) be financial, contrary to the more traditional view of a firm that is primarily accountable to its shareholders. We believe that empowering academics and giving them the possibility to participate in platform governance and profit-sharing, can allow building new 'gravitational hubs' $\underline{14}$ for academic publishing and stronger academic communities.

\section{Co-design}

This principle suggests that all stakeholders are included in the development of the platform allowing to account for their needs, capacities, and aspirations $\underline{15}$. We believe that building on this principle in academic publishing is critical if we are to create platforms and infrastructures that are just and inclusive.

\section{Open Source and Open Data}

An aspiration to open source development and open data is all the more relevant for academic publishing where the concept of 'open' is being co-opted by commercial publishers to further their goals. They are also re-shaping their business models and moving from publishing to "data analytics." $\underline{16}$ Platform cooperativism can help to build a better future for academic publishing by broadening the definition of openness on open access publishing.

\section{In practice}

In more practical terms, platform cooperativism can be put to good use in the academic publishing field both for new initiatives and existing ones, and here are some ideas on how that could work. 
New initiatives, such as publishing or pre-print platforms, can leverage the concept by inviting platform users - in this case, journal editors, authors submitting their research, peer-reviewers, copyeditors, typesetters, IT developers, and funders - to become platform owners. Depending on the goals of an organisation (or a platform), ownership may imply different things. We can imagine a platform that charges commercial publishers a fee for accessing its network of reviewers, copyeditors, and IT developers. These latter would be the platform owners (while commercial publishers would not) - meaning that each owner may have a stake in the profits the platform makes by charging access or subscription fees. These profits would then be distributed among the owners according to their 'level of contribution'. Assessing the latter may be tricky $\underline{17}$ but can also be a way to incentivise certain actions and behavious. Indeed, contributions need not be exclusively monetary $\underline{18}$ and can also be in-kind (for instance, a certain number of articles published or reviewed on the platform or of hours worked for its development). By accounting for the latter, the cooperative can valorise and recognise the contributions to academic publishing that often stay invisible. Moreover, by rewarding certain actions and contributions a platform coop can help shape academic publishing behaviours, providing incentives alternative to the existing ones, for example, incentivising publishing in "ethical" or "socially_just" versus "highranking" journals. Say, a platform owner that actively participates in platform governance, and contributes to independent open access publishers more than to commercial publishers may have a larger stake in profit distribution.

In case we speak about a platform that does not make any profit, ownership would entail an ability to participate in the collective decision-making. Clever governance mechanisms would be crucial. The ability of the platform cooperative to ensure equal representation and respect of the minorities' interests would depend on the choice of the governance bodies (e.g. the Board, Thematic Committees), the distribution of powers and responsibilities among them (what body decides on what issues) and the types of owner-members that get to participate in each of them.

As for existing mission-driven but privately-owned academic publishing initiatives, platform cooperativism can provide an alternative to a buy-out by a larger player. "Exiting to community_," or selling the company to its users and thus transforming it into a cooperative, can be a viable way for such companies to keep its communityoriented mission and values intact, retaining the trust of its users. Community ownership can be a safeguard for independent academic publishing initiatives allowing to protect these from commercial interests if these go against the interests of the users they serve. 
So, now imagine that you, as a knowledge producer, have a say in how the publishing ecosystem evolves, how platforms are designed and what actors and actions are supported through institutional funding. Imagine that your numerous voluntary contributions to academic publishing are recognised and valued. Imagine that the independent platform that you use precisely because it is "mission-driven" will stay so unless you and other users collectively decide to sell it. This is the future platform cooperativism can bring to academic publishing.

\section{Tread more essays in the "Business of Knowing" summer series $\square$}

\section{Footnotes}

1. First proposed and popularised by Trebor Scholz in his article Platform Cooperativism vs. the Sharing_Economy $\_$

2. https://www.ica.coop/en

3. https://platform.coop $/ \Perp$

4. Or 'being acquired by' in business parlance $€$

5. See, for example the Kinfolk coop that is working to support black-owned

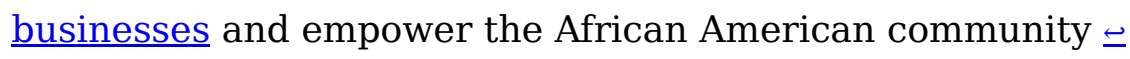

6. E.g. see a discussion of the recent acquisition of ProQuest by Clarivate Analytics in $\underline{\text { Stein et al. (2021), also see } \subseteq}$

7. While the concept was introduced in 2014 , the first mention of it that we found with regard to academic publishing dates back to $\underline{2016}$.

8. See for example a discussion in Andrews (2020). as well as the Liberate Science initiative supported through a Shuttleworth Foundation grant and Quartz OA initiative supported by the Grant for the Web $\subseteq$ 
9. see for example the controversy around Knowledge Unlatched that is sometimes referred to as a 'cooperative' but actually belongs to a consultancy owned by a $\underline{\text { member of Springer Nature Board }} \in$

10. https://platform.coop $/ \subseteq$

11. See, for example, Adema and Moore (2018), Eve (2014). and (2015) as well as Neylon et al. $(\underline{2019})$.

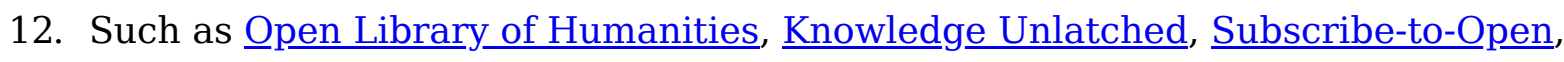

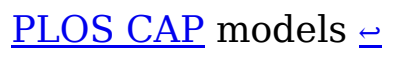

13. E.g. Knowledge Unlatched, see Montgomery_(2015).

14. As framed by Neylon et al. $(\underline{2019})$.

15. https://platform.coop $/ \Perp$

16. E.g. Elsevier positions itself as an 'a leader in information and analytics'. Also see $\underline{\text { Andrews }}$ (2020) . and $\underline{\text { Stein et al. }(2021)}$.

17. However, there are new solutions and tools - for example, Sourcecred - that allow recognising different contributions and types of value community members create. $\doteq$

18. As in most current collective publishing models where only funders enjoy governance rights $€$

\section{Citations}

1. Schneider, N. (2018). Broad-Based Stakeholder Ownership in Journalism: ESOPS, Co-ops, Blockchains. https://osf.io/d4cbv/ $\leftrightharpoons$ 